\title{
AHÉ EN CASTELLANO MEDIEVAL Y SU FUNCIONALIZACIÓN NARRATIVA EN EL CANTAR DE MIO CID
}

\author{
AHÉ IN MEDIEVAL SPANISH AND \\ ITS NARRATIVE FUNCTIONALIZATION \\ IN THE CANTAR DE MIO CID
}

\author{
Felix TACKe \\ Universität Bonn \\ felix.tacke@uni-bonn.de \\ orcid: 0000-0002-6716-7839
}

\begin{abstract}
RESUMEN: El presente artículo ofrece un análisis de los usos narrativos de (a)hé en el Cantar de mio Cid. Se mostrará que la peculiar construcción sintáctica encabezada por este elemento deíctico-presentativo constituye un importante recurso lingüístico cuyas propiedades semánticas y pragmáticas las aprovecha el narrador medieval no solamente para dirigir de modo expresivo la atención de su público y escenificar eventos imprevistos y sorprendentes (miratividad), sino también como marcador macrotextual.

Palabras clave: castellano medieval; sintaxis histórica; deixis narrativa;

pragmática; miratividad.
\end{abstract}

Abstract: The present article offers an analysis of the narrative uses of (a)hé in the Cantar de Mio Cid. The argument will be made that the peculiar syntactic construction headed by this deictic element constitutes an important linguistic resource within the narrative discourse. On the one hand, its semantic and pragmatic properties are exploited by the medieval narrator as a way to catch and direct the audience's attention and to highlight sudden or surprising events (mirativity). On the other hand, it is used as a macro-textual structuring device marking important points within the narrative.

Keywords: medieval Spanish; historical syntax; narrative deixis; pragmatics; mirativity.

Recepción: 7 de julio de 2019; aceptación: 19 de febrero de 2020. 


\section{INTRODUCGIÓN*}

La boda entre las hijas del Cid y los infantes de Carrión constituye uno de los ejes centrales del Cantar de mio Cid, lo que corrobora también la ubicación de los sucesos justo en el centro de la narración, dentro del Cantar segundo, llamado "Cantar de las Bodas" por Menéndez Pidal. Como es bien sabido, el Cid, siempre clarividente, renuncia a concluir personalmente el matrimonio y delega la responsabilidad legal en el rey:

(1) Yo las engendré amas e criásteslas vós, entre yo y ellas en vuestra merced somos nós:

afellas en vuestra mano don Elvira e doña Sol, dadlas a qui quisiéredes vós, ca yo pagado só (vv. 2086-2089).

Éste a su vez, y a petición del Cid, delega la traditio in manu ${ }^{1}$, es decir, el acto mismo de entregar sus hijas a los infantes, a Álvar Fáñez para que actúe de manero, de modo que el Cid queda desvinculado "casi por completo de la formalización de los matrimonios" (Montaner 2011a, v. 476):

(2) Respondió el rey: -Afé aquí Álbar Fáñez, prendellas con vuestras manos e daldas a los ifantes, assí commo yo las prendo d'aquent commo si fosse delant, sed padrino d'ellas a tod el velar (vv. 2135-2138).

* Este trabajo se enmarca en un proyecto de investigación llevado a cabo entre agosto y octubre de 2017 en la Universidad de Salamanca, financiado por la Cátedra de Altos Estudios del Español de la Universidad de Salamanca. Deseo expresar mi gratitud a los coordinadores de la Cátedra, sobre todo a Julio Borrego Nieto, Carmen Fernández Juncal y Carla Amorós Negre. Del mismo modo, quiero agradecer a José Antonio Bartol su generosidad y su apoyo, y a Ricardo José Muñoz y Pedro Buendía, su tiempo y su ayuda con la interpretación de la sintaxis hebrea y árabe. Aunque sea de manera póstuma, también agradezco a Federico Corriente la información que me facilitó acerca del hispanoárabe. Finalmente, quiero dejar constancia de mi agradecimiento a los lectores anónimos por sus valiosas sugerencias, así como a José Manuel Cuartango Latorre y David Porcel Bueno, por su ayuda en la revisión final de este texto.

1 "La traditio in manu o entrega de la novia, ceremonia entonces esencialmente civil, precede al rito religioso, en el que la bendición nupcial sanciona la unión” (MontAner 2011a, vv. 2225-2226). 
A continuación, en la ceremonia, Álvar Fáñez recibe en sus manos a las hijas (3) y, finalmente, concluye el acto de matrimonio dándoselas a los infantes de Carrión (4):

(3) Venit acá, Álbar Fáñez, el que yo quiero e amo: afé amas mis fijas métolas en vuestra mano; sabedes que al rey assí ge lo he mandado, no lo quiero fallir por nada de cuanto á ý parado (vv. 22212224).

(4) -Afevos delant Minaya, amos sodes hermanos; por mano del rey Alfonso, que a mí lo ovo mandado, dóvos estas dueñas, amas son fijasdalgo, que las tomássedes por mugieres a ondra e a recabdo (vv. 2230-2233).

Dada la relevancia de este complicado procedimiento formal y de los pormenores legales, no es sorprendente, pues, que el narrador se empeñe en subrayar su importancia por medio de un estilo solemne y una verbalización llena de simbolismos: por un lado, en el plano léxico, destaca la insistencia en $l a(s)$ mano(s), que "en el simbolismo jurídico medieval", como explica Montaner (2011a, v. 2088), "representa el poder de mando y la potestad que se tiene sobre algo"; por otro lado, una y otra vez, el narrador recurre, en su representación de las deliberaciones tanto del Cid como del rey y de Álvar Fáñez, al uso de construcciones de tipo <ahé $\mathrm{SN}>$, que Zaderenko y Montaner (2018, p. 22) designan "presentation formulas, which call the listeners' attention". Éstas, que propongo denominar construcciones deíctico-presentativas para evitar confusiones terminológicas (cf. infra), representan la expresión lingüística de actos de mostración que sirven, prototípicamente, para dirigir la atención y crear un marco de atención conjunta. En el contexto esbozado, sirven para verbalizar, de la manera más expresiva, la entrega solemne de las hijas del Cid y de la transmisión de la responsabilidad, así como para marcar los sucesos como importantes en el contexto narrativo. Tienen, en consecuencia, una doble función atencional: marcan la importancia de los actos dentro de la interacción verbal de los personajes implicados a la vez que subrayan la relevancia en el Cantar.

Ahora bien, el uso de (a)hé en el Cantar de mio Cid no se limita a verbalizar actos de mostración en la interacción de los 
personajes, sino que constituye, además, un procedimiento lingüístico notable dentro del discurso del narrador en su comunicación con el público, como se observa en el ejemplo (5). Aquí, el narrador destaca la llegada de Álvar Fáñez mediante un acto de mostración lingüístico que da al acontecimiento una lectura de brusquedad y de sorpresa al mismo tiempo:

(5) De missa era exido essora el rey Alfonso, afé Minaya Álbar Fánéez, dó llega tan apuesto; fincó los inojos ante tod el pueblo, a los pies del rey Alfonso cayó con grand duelo, besávale las manos e fabló tan apuesto (vv. 1316-1320).

Como veremos, son varios los usos de este tipo de expresión en el discurso narrativo. Tal y como se puede observar en la narración medieval épica y caballeresca en general, el narrador funcionaliza las construcciones deíctico-presentativas y la semántica atencional propia que las caracteriza para fines comunicativos o, más precisamente, narrativos diversos. Junto con ciertas "fórmulas de transición" (Montaner 2011, pp. 407 ss.), como (ý) veriedes ${ }^{3}$, se usan tanto para "la apelación al auditorio" como para "el acercamiento de la narración al auditorio", como afirma Montaner (p. 421) en su estudio de la "voz del narrador". Esta llamada "segunda voz" del narrador tiene "the function of directing" (Luongo 2018, p. 219) y se hace oír, en muchos casos,

2 La traducción propuesta por Montaner (2011a), “«Ved aquí a Minaya Álvar Fáñez, a dónde llega tan oportunamente», o «tan gentilmente»" (v. 1317), capta perfectamente el sentido, aunque el adverbio relativo dó se puede interpretar, en textos medievales como éste, como sinónimo de que, lo que daría: 'que llega tan oportunamente'. Respecto al uso de conjunciones locativas para introducir oraciones subordinadas predicativas en las lenguas románicas medievales, cf. TOBLER 1899, p. 67.

${ }^{3}$ Según Menéndez Pidal (Poema de mio Cid 1929), el uso de expresiones como odredes y veriedes en la épica castellana remite a la tradición francesa y representa "un verdadero lugar común de las chansons". Con este procedimiento, "el juglar se dirige a sus oyentes y procura sugerirles una viva representación de lo que va a narrar" (p. 39). No obstante, el origen de este recurso es más antiguo, como ya demostró Curtius refiriéndose a la épica virgiliana. Se trata, pues, de un topos latino que entró en la épica castellana a través de la francesa. De ahí que, a partir de los estudios de Curtius, también se hable de "cernas-Formel” (1949, p. 28), es decir, fórmula cernas (< lat. cernas '(que) observes'). 
at the crucial moments of the story. As it has become evident, we are dealing with interventions aimed at keeping the spectators' attention (phatic function), and making them participate in the events being narrated by transforming them into eye- or ear-witnesses of their unfolding (conative function) $(i d .)^{4}$.

La presencia de esta voz es típica para la narración épica, lo que corrobora la comparación con los textos franceses. Afirma Marnette (1999, p. 186) al respecto:

Les chansons de geste tendent à présenter les auditeurs/ lecteurs comme témoins potentiels de l'action qu'elles décrivent. En employant des verbes au subjonctif imparfait (ö̈ssiez, veïssiez...), le narrateur indique ce que ceux-ci auraient pu voir, entendre ou penser s'ils avaient été "sur place"... Le narrateur introduit donc le point de vue, l'angle de vision de ces auditeurs/lecteurs, au lieu du sien propre.

Es más, entre los elementos a disposición del narrador figura, también en francés antiguo, un elemento deíctico-presentativo, ez (vos), que sirve, precisamente, para "associer les auditeurs / lecteurs à l'action et de les transformer en témoins”. Y, tal como se observa en el uso de (a)hé en el ejemplo (5), los enunciados encabezados por $e z$ (vos) se combinan frecuentemente con predicados de movimiento (o bien: de cambio de estado) y sirven, de este modo, para la introducción de un personaje en una determinada escena, así como para la creación de efectos de sorpresa: “Ce mouvement se fait de l'extérieur vers l'intérieur de sorte que le présentatif introduit sur la scène un personnage qui ne participait pas à l'action. On a donc l'impression que le personnage pénètre tout à coup dans le champ de vision des auditeurs/lecteurs" (id.).

Dado que el potencial pragmático inherente a las construcciones deíctico-presentativas, sobre todo respecto a su uso en el discurso narrativo, ha sido apenas estudiado en la tradición filológica hispánica ${ }^{5}$, este artículo pretende llenar ese hueco por

${ }^{4} \mathrm{El}$ autor se refiere al "schema of oral communication and to the functions Jakobson connected to it in his study «Linguistics and Poetics»" (LuONGO 2018, p. 219, n. 25).

${ }^{5}$ En comparación, las construcciones basadas en elementos análogos como ez (vos), en francés antiguo, y voici/ voilà, en francés moderno, han sido objeto de toda una serie de estudios, entre los cuales hay también algunos que se dedican a sus funciones narrativas y discursivas. Cf., por ejemplo, las 
medio de un análisis detenido de las ocurrencias en la obra cumbre de la épica castellana. Para llegar a este fin, en el segundo apartado se expondrán las características sintácticas, semánticas y pragmáticas básicas de las construcciones deíctico-presentativas y se tratará la cuestión de su etimología junto con un resumen del estado actual de la investigación. Acto seguido, en el tercer apartado pasaremos a la definición del enfoque teórico y metodológico y definiremos el corpus. Finalmente, en el cuarto ofreceremos un análisis cualitativo de la funcionalización narrativa de <ahéSN> en el Cantar de mio Cidy terminaremos nuestra exposición con una conclusión que tiene la voluntad de abrir nuevas perspectivas de investigación.

CONSTRUCCIONES DEÍCTICO-PRESENTATIVAS:

CARACTERIZACIÓN, ORÍGENES Y ESTADO DE LA INVESTIGACIÓN

Las construcciones deíctico-presentativas reproducen verbalizaciones de actos de mostración. Éstos constituyen una tarea comunicativa fundamental (y acaso la más importante) de la "comunicación cooperativa humana", puesto que crean "atención conjunta" (joint attention; Tomasello 2008), es decir, dirigen la atención de un interlocutor a una entidad o estado de cosas para situar tal entidad en el marco de la atención conjunta (joint attentional frame). Su realización puede ser gestual o lingüística, o incluso puede combinar los dos canales. En la teoría del lenguaje de Coseriu (1992), que distingue entre el nivel universal (el hablar en general), el nivel histórico (el hablar en una lengua particular) y el nivel individual (el hablar en una situación única determinada y según tradiciones discursivas), los actos de mostración lingüísticos, aparte de tener una función referencial (nivel universal), se ubican dentro de este último nivel, ya que conciernen a la interacción entre hablantes y constituyen, por lo tanto, una "función discursiva".

Ahora bien, en muchas lenguas -no en todas-, hay construcciones específicamente destinadas a cumplir con esta función como parte inherente de su significado. Consecuentemente, éstas constituyen una "función lingüística particular". Tal es el caso del latín y de las lenguas románicas. En español contem-

indicaciones acerca de $e z$ vos en Marnette 1998 y Oppermann-Marsaux 2006 y 2007, pp. 238-240. 
poráneo, siguiendo la pauta sintáctica latina $<$ ecce $\mathrm{SN}>$, es la construcción española <he aqui $\mathrm{SN}>(<\mathrm{esp}$. ant. [a]hê) la que representa esta función, junto con una construcción de creación nueva, <aqui está $\mathrm{SN}>$, que ha venido asumiendo, desde el siglo $\mathrm{xv}$, la casi totalidad de sus usos ${ }^{6}$. Por lo tanto, en el lenguaje contemporáneo, a diferencia de las construcciones análogas italiana <ecco $\mathrm{SN}>$, francesa <voici/ voilà $\mathrm{SN}>$ y catalana <vet/ veus/ heus aquí/ aci $\mathrm{SN}>$, la española $<$ he aqui $\mathrm{SN}>$ está marcada como formal, literaria o incluso arcaica, y su uso se restringe, casi exclusivamente, a la deixis discursiva (v.gr., he aqui dos ejemplos). No era así en castellano medieval. Entonces, la pauta sintáctica de <ecce $\mathrm{SN}>$ constituía la expresión típica de esta función. Entre los elementos deícticos que podían encabezar la construcción se encontraba, ante todo, el elemento deíctico-presentativo (a)hé (frecuentemente fe o afe en la grafía medieval; cf. infra, n. 12), pero también se documenta el uso de imperativos propiamente dichos como cata/ catad, evas/ evad/ evades, mira/ mirad, así como de ves/veis/vedes/veedes/ved (estos últimos usados sobre todo en el ámbito de la deixis discursiva).

Sintácticamente, en su manifestación prototípica, la estructura <ecce $\mathrm{SN}>$ no podría ser más simple: la encabeza un elemento deíctico-presentativo que, en el caso del lat. ecce y el esp. (a)hé, no se ajusta a ninguna clase de palabras tradicional ${ }^{7}, \mathrm{y}$ que, además, rige un acusativo ${ }^{8}$. Éste, a diferencia de las cons-

${ }^{6}$ Este desarrollo concierne también, aunque en menor medida, al uso de la construcción portuguesa <eis (aqui) $\mathrm{SN}>$, frente al tipo <aquí/ cá está $\mathrm{SN}>$. Para un estudio histórico dedicado a la sustitución paulatina de $<$ he aquí $\mathrm{SN}>$ por construcciones de tipo $<$ aquí está $\mathrm{SN}>\mathrm{y}<$ aquí tienes $\mathrm{SN}>$ a partir del siglo Xv, véase TACKE en prensa.

${ }^{7}$ El problema de su clasificación se da en todas las lenguas en que existe (latín, lenguas románicas, lenguas semíticas) y se discute en casi todos los estudios relevantes. No se pueden resumir aquí todas las propuestas al respecto, aunque sí las tendencias: por su semántica deíctica, son muchos los diccionarios (como, por ejemplo, el $D L E$, s.vv. ahé, $h e^{1}$ ) y las gramáticas que le ponen la etiqueta "adverbio", a pesar de que sus características sintácticas no se ajustan a esta categoría. Por falta de categoría adecuada, muchos optan por denominarlo simplemente "interjección" o "partícula (demostrativa)". Esta última denominación nos parece más adecuada, si no se la quiere definir como miembro de una categoría sui generis, lo que indudablemente es. Para un tratamiento extenso de la cuestión, cf. TACKE en prensa a.

${ }^{8}$ Es de notar, sin embargo, que en la diacronía del propio latín el estatus sintáctico cambió de acusativo en latín antiguo a nominativo en latín clásico (por ejemplo, en Cicerón), para volver al acusativo en latín tardío (cf. TLL, s.v., y $O L D$, s.v.). 
trucciones existenciales de tipo $<$ hay $\mathrm{SN}>$ (a veces también llamadas "presentativas"), puede ser constituido tanto por un SN definido como indefinido ${ }^{9}$. En cambio, sus características semánticas y pragmáticas son más complejas. Las constituyen lo que Lakoff (1987, pp. 489 ss.) denomina el "modelo cognitivo idealizado del acto de mostración" (idealized cognitive model; en breve: pointing-out ICM). Este modelo explica, entre toda una serie de propiedades que no podemos exponer aquí ${ }^{10}$, las características temporales y aspectuales (anclaje en el momento de la enunciación, imperfectividad). Además, implica que se trata de una "speech act construction" (p. 474), o sea, una construcción que representa un acto de habla directivo. Respecto a la estructura informativa, las construcciones deícticopresentativas sirven, en su realización prototípica, para marcar una entidad como foco (se trata de una "morphosyntactic focus-marking device"; Lambrecht 1994, p. 218). Representan, asimismo, un tipo de oraciones téticas, puesto que sirven frecuentemente para introducir referentes nuevos o no activos en el discurso y construyen la proposición entera como focal: "X está aquî", "X acaba de llegar aquî"11. En cambio, si el SN representa un referente ya activo en el discurso y se realiza en forma de pronombre, seguido por una predicación secundaria $(<[a]$ hé-PRO + PREDICADO $>)$, el foco cae en el predicado y se emplea para focalizar, de manera expresiva, un nuevo estado de cosas relacionado con la entidad en cuestión y anclado en el momento de la enunciación.

El origen de (a)hé ( $\left.f e, a f e ́, h e, a h e^{12}\right)$ ha sido objeto de debate, a veces controvertido, desde finales del siglo xIx (cf. el exce-

9 La llamada "restricción de definitud" con las existenciales conoce numerosas excepciones y hay determinados usos que sí permiten el empleo de SN definidos (cf., p.ej., Pons Rodríguez 2014 y De Benito 2016). No obstante, en el caso de las construcciones deíctico-presentativas, el empleo tanto de SN definidos como indefinidos se da ya a partir del uso prototípico.

${ }^{10}$ Véase Tacke (2020, cap. 2) para un tratamiento extenso de sus propiedades.

11 Para un estudio de la estructura informativa de construcciones análogas en francés, véase LAMbrecht 2000 y KARSSENBERG et al. 2018.

${ }^{12}$ La variación de la grafía en los textos medievales $(f e, a f e ́, h e, a h e ̂)$ ha llevado, a veces, a tratarlos separadamente y a suponer orígenes (e incluso perfiles funcionales) distintos. Por razones de brevedad, damos un resumen de las diferentes propuestas etimológicas sin entrar en detalle en cada una de ellas. Conforme al punto de vista actual, consideramos, junto con Viejo SÁnchez (2017, pp. 166 ss.) y Rodríguez Molina (2018, p. 141), que 
lente panorama en Malkiel 1982, pp. 255-262). A diferencia de los elementos análogos en francés antiguo $(e z)$ e italiano (ecco), que sí derivan del elemento latino ecce/ eccum, el español, "conversely, for once acts like an obnoxious trouble-maker" como afirma, con razón, Malkiel (p. 256). Las propuestas etimológicas van desde formas imperativas del verbo vidère (Diez 1887 [1853]) o, más frecuentemente, del verbo habēre (Bello 1860 [1847], § 581; Meyer-Lübke 1890-1902, t. 2, § 242; Ford 1903; Pietsch 1904 y 1904a) ${ }^{13}$, pasando por propuestas que ven su origen en el elemento deíctico-presentativo latino èn (MeyerLübke, en su $R E W, \S 2866$ vs. $R E W, 3^{\mathrm{a}}$ ed., $\S 4089 \mathrm{a}$ ) o en exclamaciones relacionadas con fide 'fé' (Ascoli 1886-88, p. 7), hasta la propuesta de Menéndez Pidal (1911, s.v. fe), según la cual (a)hé deriva del elemento deíctico-presentativo árabe $h \bar{a}$ (ه) y, más precisamente, de la variante hispanoárabe $h \bar{e}$. Esta última propuesta es la que hoy se acepta generalmente. Ya fue adoptada por el DRAE en su $14^{\text {a }}$ edición de 1914, seguido por el $D C E C H$ (s.v. $h e$, véase la edición actual, DLE, s.v. he, $1^{\text {a }}$ acep.) y el $D A A L$ (s.v. $h e)^{14}$. Malkiel (1982) se suma a esta última hipótesis sin querer excluir, por cierto, una probable influencia de (ad) fide $(m)$, considerando, por tanto, que se trata posiblemente de un caso de "polygenesis" (p. 262) ${ }^{15}$.

el grafema $<\mathrm{f}>$ en $f e /$ afé representa el sonido / $\mathrm{h} /$, aspirado en la época y frecuentemente transcrito de este modo en palabras de origen árabe.

${ }^{13}$ Cf. también la exposición en TACKE en prensa a. El análisis (incorrecto) de he como forma imperativa de haber se mantiene incluso en la NGLE (t. $1, \S 4.13 \mathrm{e}$ ), donde se afirma, erradamente, que "las formas del imperativo he, habe (ya perdida) y habed (que solo se documenta esporádicamente) son hoy arcaicas. La primera se ha fosilizado en la fórmula presentativa he aquí, henos ahora o hete aquî.

14 En la lista de "Menéndez Pidal's followers", quienes "rallied to the support of the Madrid scholar's Orientalist thesis" (MALkiEL 1982, p. 258), figura también Lapesa, pero el $D R A E$ fue la primera obra en considerarla (Malkiel, loc. cit., afirma erróneamente que sólo adoptó esta etimología a partir de su $19^{\text {a }}$ edición de 1970).

15 Advierte, en este contexto, que " $[\mathrm{t}]$ he safest modus operandi is henceforth to shunt off the part once played in reconstruction by FIDE from center-stage to the wings; that part, our safest guess would be, involved a supervenient optional elaboration, of minor relevancy to the main thrust of our etymological quest" (pp. 259 ss.). Ridruejo (2007, pp. 541-543) y Viejo SÁNchez (2017) proponen una hipótesis similar, pero sin tener en cuenta el razonamiento de Malkiel. 
Ahora bien, una cuestión poco ponderada en los estudios mencionados es el origen de la $a$ - en $a h e^{16}$. El DLE (s.v. $a h \hat{e}$ ) remite a la entrada $a^{-1}$, donde se da como étimo el lat. AD-. No obstante, esta procedencia nos parece poco probable visto el origen árabe de he y luego de considerar que ninguno de los demás elementos románicos consta de una combinación semejante, menos con una preposición. Más probable nos parece que $a$-constituye un préstamo árabe del mismo modo que $h e$, ya que el hispanoárabe contaba con un elemento (prefijado) de esta forma con función de vocativo o presentativo (cf. Corriente et al. 2015, p. 216, n. 55, y DFDA, s.v. Alif $\left./{ }^{*}\{P\}\right)^{17}$. Vocativos de todo tipo, dada su función atencional, sí que se combinan frecuentemente con construcciones deíctico-presentativas en todas las lenguas románicas y en todas las épocas. Como variante de he, el elemento ahé se usa en toda la Edad Media, y los autores optaban por una u otra de las dos formas, antes de que la bisilábica cayera en desuso ${ }^{18}$. En este ámbito, es de notar que el Cantar de mio Cid se nos presenta como uno de los pocos textos que aún conserva una opcionalidad morfosintáctica árabe que poco después, probablemente por causa de su aislamiento funcional en el sistema lingüístico, va a desaparecer.

16 Es curioso que, en la gran mayoría de los textos citados, incluido el estudio del propio Menéndez Pidal, la cuestión de la $a$-ni siquiera se haya planteado. Últimamente, Corriente refiere a ahá, préstamo del árabe andalusí. Cf. Corriente 2018, p. 170, y 2018a, p. 30; además, cf. infra, n. 17.

${ }^{17}$ La historia de las lenguas tanto indoeuropeas como semíticas muestra que no es fácil clasificar las partículas demostrativas según funciones sintácticas más allá de su valor deíctico (véase supra, n. 7). El $a$ - hispanoárabe en cuestión puede ser marca de vocativo o bien una partícula presentativa del mismo valor que $h \bar{a}$. La combinación de elementos demostrativos semánticamente equivalentes era muy frecuente. Según F. Corriente (comunicación personal, 27.I.2018), "tanto / $\overline{\mathrm{a}} /$ como / hā/ son partículas presentativas, que se pueden usar y acumular para llamar la atención sobre un objeto, y son muchos los dialectos que han conservado el giro, aunque generalmente sustituyendo el segundo elemento por el pronombre personal de tercera persona, p.e., en egipcio / $\mathrm{ahu} / \mathrm{fem}$. /ahī/ etc., o, en el mismo andalusí, el ejemplo de mi diccionario /āhu yatġazzal/ 'hételo componiendo poesía erótica'”.

18 Véase el comentario de Juan de Valdés en su Diálogo de la lengua: "ahé, que quiere dezir ecce, ya no se usa, no sé por qué lo avemos dexado, especialmente no teniendo otro que sinifique lo que él" (cf. DCECH, s.v. he). Sí se continuó usando he, cada vez más frecuentemente, combinado con aqui (hoy obligatorio), aunque, con el tiempo, fue sustituido casi completamente por la construcción <aquí está $\mathrm{SN}>$ (véase supra, n. 6). 
Fundada en un amplio análisis histórico-comparativo de todas las lenguas románicas, que abarca también el uso de elementos semejantes en árabe y hebreo ${ }^{19}$, nuestra tesis es que la construcción $<(a) h e ́ \mathrm{SN}>$ continúa el esquema sintáctico heredado del latín, mientras que el continuador iberorromance del elemento deíctico-presentativo latino fue sustituido por un elemento de características sintácticas y semánticas parecidas a las del hispanoárabe: el hē identificado por Menéndez Pidal. Una tesis similar -aunque su estudio ha recibido poca atención-fue adelantada por Malkiel (1982, pp. 261 ss.):

We advanced one step further in connection with the controversy that has surrounded for a century OSp. (a)fé, mod. he (aqui), Ptg. eis aqui, concluding from Republican Latin, Old French, Italian, and Sardinian evidence that the Iberian peninsula could very well have inherited from Latin some such deictic as èn, em, or *ec, accompanied by sets of characteristic constructions. This legacy, we argued, was apt to be eroded, at the normal rate of attrition, prompting the speakers to appeal to an assortment of substitute words, with faithful preservation of the immediately recognizable original syntactic framework.

Es revelador que lo mismo ocurrió en rumano, donde el elemento en cuestión (iată) se tomó del antiguo eslavo meridional (búlgaro) eto (Zafiu 2015, p. 428). Por lo tanto, siguiendo este razonamiento, se trata de un cambio de perspectiva, ya que, en vez del elemento, se toma como punto de partida la construcción para reconstituir la continuidad latino-romance (cf. Tacke 2020a).

De este modo se revela asimismo otra continuidad y otro paralelismo con las demás lenguas románicas: los usos, y más precisamente, la funcionalización narrativa de este peculiar tipo de construcciones. El estado de la investigación en cuanto a tales funciones se limita a pocos estudios. El primer panorama de los usos medievales lo presentó Pietsch (1904), seguido por Menéndez Pidal, quien ofrece en el Vocabulario (1911, s.v. fe) del Cantar un pequeño resumen de las ocurrencias de (a)hé. Desde entonces, sin embargo, se ha dedicado poca atención a este

${ }^{19}$ El presente estudio forma parte de un proyecto monográfico más amplio que abarca la diacronía y la funcionalización de este tipo de expresiones en todas las lenguas románicas (TACKe 2020). Por razones de espacio, tenemos que limitarnos aquí a aludir a los resultados más destacables. 
ámbito, hasta que, recientemente, dos estudios se han consagrado a clasificar los usos de (a)hé en las traducciones bíblicas medievales: Enrique-Arias y Camargo Fernández (2015), basándose en más de 600 ocurrencias extractadas del corpus Biblia Medieval, estudian sus funciones -como marcador discursivoa partir del uso respectivo de ecce y hinne (הנחה) en los textos originales, mientras que Viejo Sánchez (2017), desconociendo el estudio anterior, analiza su uso en la Biblia medieval romanceada desde una perspectiva fraseológica. No obstante, centrados más en cuestiones de etimología o de clasificación (tanto del elemento como de los usos), ninguno de estos estudios se presta a un análisis pormenorizado del discurso narrativo y del papel que (a)hé desempeña en él.

\section{MARCO TEÓRICO, METODOLOGÍA Y CORPUS}

\section{<“(A)hé” SN> como construcción}

En el presente estudio se aplica una perspectiva funcionalista y cognitivista al análisis del uso de las expresiones en cuestión (cf. el estudio de las there-constructions inglesas de Lakoff 1987 y la comparación con las construcciones francesas de Bergen \& Plauché 2005), de ahí que se sitúe en el marco teórico de la gramática cognitiva (Langacker 1987 y 2008) y de la gramática de construcciones (Goldberg 1995 y 2006; Croft 2001). Nuestro interés, por tanto, no se limita a un análisis estrictamente sintáctico, sino que además tratará de tener en cuenta el procesamiento cognitivo tanto por parte del narrador como del público o lector. Sólo de este modo, según nuestro entender, se llegará a tener una comprensión profunda del funcionamiento de las construcciones deíctico-presentativas. La cuestión que se plantea respecto al narrador es por qué opta, ahí donde recurre a su uso, por un acto de mostración lingüístico y no por otra expresión. En cuanto al público/ lector como receptáculo, la cuestión planteada comprende el efecto que tienen la semántica y el potencial pragmático de las construcciones deíctico-presentativas en la concepción del imaginario narrativo y considera los contextos precisos en que el narrador los inserta.

El analizar $<(a) h e ́ S N>$ en el marco de la gramática de construcciones implica comprender la construcción como unidad de forma y de significado. En este sentido, todos sus compo- 
nentes forman parte de la expresión de un mismo contenido conceptual: el acto de dirigir la atención del interlocutor a una entidad o un estado de cosas. El verso 152 del Cantar es un buen ejemplo para describir la morfosintaxis típica de la construcción $^{20}$ :

(6) Afévoslos a la tienda del Campeador contado (v. 152). ${ }_{\mathrm{A}}[\text { Afé }]_{\mathrm{A}^{*}}[\mathrm{vos}]_{\mathrm{B}}[\mathrm{los}]_{\mathrm{C}}[$ a la tienda del Campeador contado $]$.

El elemento deíctico-presentativo (a)hé (A) que encabeza la construcción representa, de forma icónica, el gesto. Opcionalmente, se le adjunta un complemento indirecto $\left(\mathrm{A}^{*}\right)$, un dativo ético, que representa la apelación al interlocutor ${ }^{21}$. La entidad mostrada se designa con un complemento directo (B), es decir, un SN que se expresa, según el contexto (referente no activo vs. activo), en forma completa o mediante un pronombre. Finalmente, las construcciones deíctico-presentativas contienen casi siempre un complemento locativo ${ }^{22}$, o bien otro tipo de complemento predicativo $(\mathrm{C})$ que añade información remática al referente que constituye el centro de atención conjunta previamente establecido (B).

En cuanto al perfil semántico-pragmático, se puede diferenciar entre un valor prototípico, que es el de 'dirigir la atención a algo concreto visible en el contexto situacional', y varios valores que derivan de él como usos extendidos. La denominada "deixis «del ahora»" o "del estado" (now deictic y stative deictic; cf. Bergen y Plauché 2005), por ejemplo, sirve para dirigir la atención a una nueva localización o a un nuevo estado de un referente casi siempre ya activo. Así, pues, en (6), se dirige la atención a la llegada de Martín Antolínez y Rachel y Vidas a la localización susodicha, justo en el momento de la enunciación, por lo que se sobreentiende la indicación temporal ahora.

${ }^{20}$ Nótese que, si se estudia la variedad de sus ocurrencias, en el Cantar de mio Cid se observa una morfosintaxis igual a la de construcciones románicas análogas en contextos similares. Cf. TACKE, 2020 y 2020a.

${ }^{21} \mathrm{El}$ uso del dativo ético vos es típico para la literatura épica medieval y se limita a aquella época. En español moderno, en cambio, es frecuente -ahí donde aún se usa- combinar he con el pronombre dativo del singular te en formas como hételo aqui (cf., por ejemplo, DEA y DUE, s.v. he).

${ }^{22}$ Véase el capítulo de García-Miguel (2006, pp. 1279 ss.) sobre complementos locativos, donde se trata brevemente la construcción con (a)hé junto con otras "construcciones sin sujeto", única mención que la monumental Sintaxis histórica de Company (2006) dedica a esta forma. 
En cambio, en (7), la llegada es metafórica, o sea, el narrador dirige la atención al hecho de que Álvar Fáñez acaba de ejecutar las órdenes que el Cid le había dado anteriormente:

(7) Afevos todo aquesto puesto en buen recabdo (v. 1255).

El anclaje temporal junto con el participio (puesto en buen recabdo 'puesto en orden') crean aquí el valor de perfectividad del nuevo estado de cosas. De este modo, el uso de la construcción deíctico-presentativa impone claramente una interpretación temporal y aspectual, ya que se dirige la atención a una nueva localización o un nuevo estado de cosas que vale en el momento de la enunciación (o bien a partir de él). Nótese, sin embargo, que, si se recurre a construcciones deícticopresentativas dentro del discurso narrativo, los referentes y los lugares son imaginados y se ubican en un espacio mental narrativo, no físico. Se trata, por lo tanto, de casos de deixis "en fantasma" en el "lenguaje épico", según la terminología de Bühler (1950). En este caso, se habla asimismo de "deixis narrativa" (cf. Lakoff 1987, p. 531), pues sirve, como ya hemos mencionado, para convertir al público (o a los lectores) en testigo de la acción descrita (cf. Marnette 1999, p. 186).

\section{Construcciones deictico-presentativas como "expresiones mirativas"}

Si se pasa del análisis de la sintaxis construccional interna y sus valores pragmáticos inherentes al estudio de su inmersión en el contexto (narrativo) o, dicho de otro modo, a la sintaxis externa, se revelan las funciones discursivas. Es aquí donde el concepto funcional de la miratividad (mirativity), acuñado en tipología lingüística desde finales de los años noventa (cf. DeLancey 1997 y 2001, y Aikhenvald 2012), nos resulta sumamente oportuno: éste, aplicado sobre todo a lenguas que la expresan en el plano gramatical (partículas, morfemas, flexión verbal, etc.), describe el marcado de una información no según su origen (evidencialidad), sino según su estatus; se trata de marcar la información expresada como imprevista, sorprendente o, por lo menos, nueva frente a informaciones ya asentadas. Las lenguas que, como el español, no disponen de marcadores gramaticales propios para expresar esta función semánticopragmática, la pueden expresar, sin embargo, mediante otros 
recursos, tanto léxicos (por ejemplo, ¿Qué sorpresa!, es sorprendente que) como gramaticales secundarios (por ejemplo, ciertos usos de oraciones condicionales ${ }^{23}$ y, en español, el uso del llamado "foco mirativo"; cf. Cruschina 2019). El uso de construcciones deíctico-presentativas exhibe, ya por su semántica básica de dirigir la atención, una afinidad notable con el marcado de miratividad. Ésta se manifiesta en sus usos tanto en latín y las lenguas románicas como en otras lenguas: por ejemplo, en el hebreo bíblico, donde se ha descrito por primera vez (MillerNaudé \& van der Merwe 2011; ya antes, Wehr 1984, pp. 98 y 134 ss., trata estos mismos efectos pragmáticos bajo el término surprisatif; cf. el tratamiento extenso en Tacke 2020, cap. 3.6). A la luz de este enfoque, tal como vamos a mostrar en este estudio, el recurrir a construcciones deíctico-presentativas por parte del locutor o narrador puede formar parte de lo que se llama "mirative strategies" (Aikhenvald 2012, p. 462), es decir, estrategias discursivas cuya función es el marcado de la importancia (sorpresa, novedad, relevancia) de ciertos eventos narrados.

\section{Corpus}

El Cantar de mio Cid cuenta con 31 ocurrencias de (a)hé. Entre ellas, 11 ocurrencias conciernen a usos prototípicos que se ubican en el discurso directo entre personajes (deixis situacional o "ad oculos" en el "lenguaje dramático"; Bühler 1950), como el enunciado por parte del Cid "Afé los moros a ojo, idlos ensayar" (v. 2381) y los actos presentativos que ya discutimos en la introducción (cf. supra). En cambio, 16 usos se ubican dentro del discurso narrativo, es decir, en enunciados del narrador (deixis narrativa) que pertenecen a la llamada "segunda voz". Cuatro ocurrencias encabezan exclamaciones como "iAfé Dios del cielo, que nos acuerde en lo mijor!” (v. 1942), que son difíciles de clasificar (cf., al respecto, Viejo Sánchez 2017). Siguien-

${ }^{23}$ Considérese el ejemplo que da DeLancey (2012, p. 534): siguiendo al enunciado de un primer hablante, que viene desde fuera de la casa, como "The rain's stopped, it's beautiful out! Let's go work in the garden!", el enunciado (a) se interpretaría como "mirativo", es decir, expresa la sorpresa por parte del interlocutor, puesto que ya sabe, por lo anteriormente dicho, que ya no llueve; en cambio, el enunciado $(b)$ se interpretaría meramente como constatación: (a) "Oh, if it's not raining, I'm gonna go for a run"; (b) "Since it's not raining, I'm gonna go for a run”. 
do el enfoque ya definido, en este artículo sólo se estudiarán los 16 usos narrativos. Intentamos llegar así a un mejor entendimiento del ámbito de uso hasta ahora menos estudiado en filología hispánica: la funcionalización de las construcciones encabezadas por (a)hé en la comunicación entre el narrador y su público. Éstos, que representan más de la mitad del total de las ocurrencias, son mayoritarios. Puesto que no se trata ni de un estudio fonológico ni gráfico, usamos la edición crítica, hoy canónica, de Alberto Montaner (Cantar 2011) sin considerar las alternancias gráficas en el manuscrito.

FUNCIONALIZACIÓN NARRATIVA DE $<(A) H E ́$ SN $>$ EN EL CANTAR DE MIO CID

Para estudiar el uso narrativo de las construcciones deícticopresentativas en el Cantar, recurrimos al concepto de current discourse space, tal como lo define Langacker (2001), ya que nos permite describir el desarrollo y procesamiento dinámicos del discurso. El espacio discursivo actual abarca la situación comunicativa, los contextos y el saber conjunto de los interlocutores. Pertinente para nuestro estudio es la división del procesamiento del discurso en "attentional frames" (p. 156). Para aplicar este concepto dinámico, son tres los "marcos atencionales" que hace falta tomar en cuenta: un marco atencional actual, uno que le precede, o sea, el contexto anterior inmediato, y un marco atencional que el interlocutor anticipa basándose en su experiencia y, según el caso, en sus conocimientos de discursos semejantes. Estos marcos atencionales corresponden, en general, a unidades de entonación (cf. Chafe 1994, p. 69); aplicados al estudio de nuestro texto épico, corresponden formalmente a un verso o un hemistiquio y, en cuanto al contenido, a la representación lingüística de escenas o partes de ellas.

Clasificamos las 16 ocurrencias de deixis narrativa según la interpretación pragmática que imponen a propósito de las entidades mostradas, ya que, como veremos, un acto de mostración lingüístico puede desempeñar funciones diferenciadas según el contexto y la sintaxis (externa) en que se inserta. Por lo que toca al Cantar, hemos identificado cuatro funciones narrativas distintas respecto a la entidad mostrada: la verbalización de 1) su llegada reciente, 2) su llegada en curso, 3) su aparición repentina y 4) el marcado de cambio de foco narrativo. 
Llegada reciente (valor perfectivo)

En siete casos, la construcción $<(a) h e ́ \mathrm{SN}>$ se usa para marcar la llegada de un personaje a un lugar determinado:

(8) Martín Antolínez cavalgó privado con Rachel e Vidas, de voluntad e de grado. Non viene a la puent, ca por el agua á passado, que ge lo non ventassen de Burgos omne nado. Afévoslos a la tienda del Campeador contado, assí commo entraron, al Cid besáronle las manos (vv. 148-153).

(9) Con aqueste aver tórnanse essa conpaña, felos en Castejón, o el Campeador estava (vv. 484-485).

(10) Ya s'espiden e piensan de cavalgar, el portero con ellos que los ha de aguardar; por la tierra del rey mucho conducho les dan. De San Pero fasta Medina en cinco días van, felos en Medina las dueñas e Álbar Fánez (vv. 1448-1452).

(11) Grant ondra les dan a los ifantes de Carrión. Afelos en Valencia, la que mio Cid gañó, cuando a ella assomaron los gozos son mayores (vv. 2174-2176).

(12) Por Santa María d'Alvarrazín fazían la posada, aguijan cuanto pueden ifantes de Carrión, felos en Molina con el moro Avengalvón (vv. 2645-2647).

(13) Las tres semanas de plazo todas complidas son.

Felos al plazo los del Campeador, cunplir quieren el debdo que les mandó so señor (vv. 3533$3535)$.

(14) A guisa de menbrados, andan días e noches, felos en Valencia con mio Cid el Campeador (vv. 3700-3701).

La ocurrencia (9) nos puede servir para explicar toda la clase: el verso que precede al acto de mostración ("Con aqueste aver tórnanse essa conpaña”) expresa el inicio del movimiento de las tropas dirigidas por Álvar Fáñez. En seguida, la enunciación de "felos en Castejón" anuncia su llegada en el castillo del Cid. Aunque literalmente sólo se trata de la proposición 
'ENTIDAD está en LUGAR', la semántica temporal inherente a las construcciones deíctico-presentativas, o sea, su anclaje en el momento de la enunciación, implica una interpretación aspectual de un estado de cosas como inceptivo o ingresivo ${ }^{24}$. En consecuencia, teniendo en cuenta el verso anterior, la proposición se interpreta metonímicamente como una llegada que, por falta de otra indicación, se tiene por perfectiva: 'ENTIDAD está en LUGAR [ahora]' $\rightarrow$ 'ENTIDAD ha llegado/ acaba de llegar' 25 .

En los demás casos citados, el procedimiento es semejante. Así pues, en (8), (11) y (13) se emplea, principalmente, para marcar un salto espacial, de un lugar a otro. Ahora bien, en (10), (12) y (14), se trata, asimismo, de marcar saltos temporales. En estos casos, mediante (a)hé, el narrador marca el final de un viaje de varios días anunciado e iniciado por la construcción de aspecto incoativo <pensar $d e \mathrm{~V}_{\text {Inf. }}>{ }^{26}$ unos versos antes. A diferencia de otros pasajes del Cantar en que se relata todo el itinerario a lo largo de varios versos ${ }^{27}$, aquí, por razones de economía y relevancia narrativa, el narrador prescinde de la narración del segmento que media entre el inicio de un desplazamiento y su fin. Los enunciados "felos en Medina" y "felos en Molina" constituyen, por tanto, un recurso proléptico apto para recortar la trama y marcar un salto tanto espacial como temporal. Hay que subrayar que en todos estos casos se da una continuidad referencial, marcada por el valor anafórico del clítico de objeto: la entidad, pues, persiste en el tiempo, aunque no en el espacio.

En suma, según el contexto en que se sumerge, el narrador funcionaliza este tipo de construcción para varios fines a la vez.

${ }^{24}$ En su estudio de las construcciones francesas encabezadas por voici/ voilà, LÉARD (1992, p. 124) habla de una "prise de connaissance ponctuelle" expresada por el elemento deíctico-presentativo. Para un tratamiento más extenso de las características temporales y aspectuales, véase TAckE 2020, cap. 3.5.

25 Montaner (2011a, v. 485) glosa el elemento deíctico-presentativo adecuadamente como 'ya están'.

${ }^{26}$ Cf. Montaner (2011a, vv. 10 y 643), quien la glosa como 'prepararse para', 'estar a punto de' y 'ponerse a'.

27 Compárese, por ejemplo, el viaje que inicia el destierro del Cid. El narrador, a partir del verso 391, nombra todos los lugares transitados por el Cid "con la mención de sucesivos topónimos", lo que marca su avance "siguiendo un recurso propio de la épica medieval" (Montaner 2011a, v. 396). Ahí, asimismo, emplea en dos ocasiones (vv. 391 y 394) la perífrasis pensar de andar/ cavalgar para marcar el inicio de etapas subsiguientes del itinerario. 
Por un lado, marca un salto espacial y temporal (no siempre se describen los pormenores de los viajes). Asimismo, queda claro que la nueva ubicación en el mundo narrado también marca un cambio de escena. En (9), en el verso 485, felos en Castejón tiene además una función macrotextual respecto a los acontecimientos que preceden el evento, razón por la cual Luongo (2018, p. 214) habla de un "recapitulating verse that signals the end of the branching off". Por otro lado, la función más importante reside en que el narrador capta y dirige la atención de su público de manera expresiva al personaje llegado y lo constituye como nuevo foco y punto de partida para la narración subsiguiente.

Un caso especial que deriva de esta misma función lo constituye la ocurrencia siguiente:

(15) Esto mandó mio Cid, Minaya lo ovo consejado: que ningún omne de los sos vassallos que·s' le non spidiés o no.l' besás la mano, si $\cdot$ l' pudiessen prender o fuesse alcançado, tomássenle el aver e pusiéssenle en un palo. Afevos todo aquesto puesto en buen recabdo, con Minaya Álbar Fáñez él se va consejando (vv. 1251-1256).

Basado en la misma metonimia, se trata de una extensión metafórica según el principio 'ESTADOs son LUGARES' (cf. Bergen \& Plauché 2005, p. 17): marcada por el uso anafórico del demostrativo (aquesto) y el participio (puesto), la nueva situación se conceptualiza aquí como la llegada a un nuevo estado de cosas y constituye a la vez un salto temporal dentro de la trama, pues la ejecución de las órdenes del Cid, es decir, los actos drásticos que son el quitar bienes y ahorcar a colonos y vasallos, no se expone. En cambio, la nueva situación ("todo... puesto en buen recabdo") permite seguir con la historia.

\section{Llegada en curso (valor imperfectivo)}

En otros contextos, la construcción $<(a) h e ́ \mathrm{SN}>$ marca la llegada de un personaje que aún se observa. Ocurre dos veces en el Cantar:

(16) Otorgado ge lo avié el abbat de grado. Afevos doña Ximena, con sus fijas dó va llegando, señas dueñas las traen e adúzenlas adelant (vv. 261-263). 
(17) De missa era exido essora el rey Alfonso, afé Minaya Álbar Fáñez, dó llega tan apuesto; fincó los inojos ante tod el pueblo, a los pies del rey Alfonso cayó con grand duelo (w. 1316-1319).

Dada la interpretación pragmática que tiene lugar bajo las circunstancias arriba definidas, y que -en parte- valen también para los casos (16) y (17), se infiere aquí claramente de la extensión de la construcción -siempre en el segundo hemistiquio, por una predicación secundaria mediante las oraciones relativas "dó va llegando" y "dó llega tan apuesto"- que el lector asume una perspectiva cursiva frente al evento ${ }^{28}$ : el narrador pone en escena la llegada de los personajes e invita a su público a observarla como si estuviera presente. La estructura temporal así definida constituye claramente una variante de lo que Imbs (1956, p. 273), en su análisis de estructuras parecidas en francés antiguo, describe como la coincidencia de una "action-éclaire" con una "action-durée": "Assez souvent, l'écrivain marque que l'événement nouveau, l'action-éclair, tombe dans le déroulement de l'action-durée de manière absolument imprévue" (p. 275). El hecho de que "le procédé le plus usuel et le plus efficace pour exprimer la soudaineté de l'action principale et la surprise qu'elle provoque, c'est l'emploi, en tête de la proposition principale, de l'expression es vos ou d'une de ses variantes" (p. 281) vale también -evidentemente- para el español $(a) h \hat{e}^{29}$.

Es de notar que, en esta configuración narrativa, no se produce ningún cambio de lugar respecto al verso anterior, sino que este verso sirve para caracterizar el fondo de una escena cuyo punto culminante es la llegada del personaje. Como esquema sintáctico y narrativo a la vez, los dos versos crean así un efecto fondo-figura. Hay, pues, simultaneidad temporal entre el lapso o la fase abierta por el inicio de un estado de cosas (otorgado, exido) y el punto culminante del logro de llegar. Lo que llama la atención en esta configuración es que la llegada concierne a personajes que, a diferencia del caso discutido en el subapartado anterior, todavía no están activos en el discurso inmediato -de ahí que no se construyan mediante pronombres-y no cons-

28 Acerca del adverbio relativo dó, cf. supra, n. 2. Acerca del posicionamiento cursivo del hablante frente al estado de cosas verbalizado, cf. CosERIU 1996, pp. 98 ss.

${ }^{29}$ Esta estructura, presente ya en la épica medieval, será muy frecuente en la novela medieval en prosa. Cf. TACKE 2020, cap. 5.1. 
tituyen, por tanto, el foco narrativo hasta su introducción por el elemento (a)hé. Así pues, la llegada se escenifica, por medio de la definición de un fondo que la precede, como un acontecimiento repentino o incluso sorprendente. En consecuencia, la construcción deíctico-presentativa adquiere claramente valores mirativos.

Como ya hemos mencionado, el marcado de "miratividad" concierne al estatus de la información expresada. Este marcado puede abarcar, según Aikhenvald (2018, p. 437), la siguiente gama de valores: (i) sudden discovery, sudden revelation or realization; (ii) surprise; (iii) unprepared mind; (iv) counterexpectation; (v) new information. La misma estudiosa (p. 473) destaca que en varias lenguas existen formas de marcar tal estatus en relación con (a) the speaker, (b) the audience (or addressee), o (c) the main character.

Indudablemente, el uso de las construcciones deíctico-presentativas forma parte, en el contexto aquí discutido, de estrategias mirativas con los valores de (i), (ii), (iii) y (v). Aunque el acontecimiento no pueda asombrar al narrador $(a)$-pues éste es omnisciente respecto a su narración-, sí que sorprende tanto al público $(b)$ como a los personajes $(c)$ que protagonizan la puesta en escena del fondo (el respectivo verso anterior).

\section{Aparición repentina}

A primera vista, los siguientes casos parecerían semejantes a las configuraciones ya discutidas:

(18) Cuando estas dueñas adobadas las ha, el bueno de Minaya pensar quiere de cavalgar; afevos Rachel e Vidas a los pies le caen (vv. 1429-1431).

(19) Dixo mio Cid: -iAyamos más de vagar!Afevos el obispo don Jerónimo, muy bien armado está, parávas' delant al Campeador, siempre con la buen auze (vv. 2367-2369).

(20) Assí commo acaban esta razón, afé dos cavalleros entraron por la cort, al uno dizen Oiarra e al otro Yéñego Simenoz (vv. 33923394). 
Aquí, sin embargo, las construcciones deíctico-presentativas se emplean para marcar valores mirativos aún más notables. A causa del contexto anterior, destacan, sin lugar a dudas, el "descubrimiento brusco" (valor $i$ ), la sorpresa (ii) y la mente desprevenida (iii) de los personajes.

Así, en (18), el narrador subraya mediante la incorporación de un verbo de intención (querer) en la secuencia <pensar de $\mathrm{V}_{\mathrm{INF}}>$ que la llegada de Rachel y Vidas es imprevista porque incide en una acción inminente. La perífrasis verbal es, en sí, como ya hemos mencionado (cf. supra, n. 26), incoativa. Sin embargo, nuestro análisis de (18) muestra claramente que la combinación con querer no es, como afirma erróneamente Montaner (2011a, v. 1430), "redundante, pues los dos verbos auxiliares significan lo mismo", sino que el narrador marca la intención de una acción que, en este caso concreto, no se podrá llevar a cabo por la aparición repentina de Rachel y Vidas. En este contexto, el narrador usa el verbo querer para anunciar (o bien dar indicios de) que habrá un imprevisto y crear ciertas expectativas en su público, es decir, juega con el "marco atencional anticipado".

Algo semejante ocurre en (19): la aparición del obispo batallador deseoso de dar los primeros golpes marca justamente lo contrario de lo anticipado, ya que, con el enunciado "¡Ayamos más de vagar!" en el verso anterior, el Cid había intentado frenar el ímpetu de sus tropas. Se trata, por tanto, del marcado mirativo de counterexpectation (valor $i v$ ). Finalmente, la aparición de los dos caballeros en (20) es inesperada, en la medida en que se trata de dos infantes, no mencionados antes, que piden la mano de las hijas del Cid. En el plano textual, el evento verbalizado de modo expresivo por (a)hécon valor mirativo ${ }^{30}$ marca el inicio del desenlace feliz de la epopeya, por lo que Rico (2011, p. 240) lo describe, con razón, como "un golpe de efecto".

Estos golpes de efecto con valor de brusquedad y de interrupción se plasman, aquí también, en la configuración sintáctica general de estos tres casos, es decir, en la secuencia de una oración subordinada temporal y una oración principal en (18) y (20), y en la secuencia de las dos principales en (19).

30 Nótese que Malkiel (1982, p. 259), al citar este mismo ejemplo, traduce el efecto de miratividad que crea el uso de la construcción deícticopresentativa en este contexto por medio del adverbio suddenly, o sea, en el plano léxico: "lo and behold, two knights suddenly entered". 
Cambio de escena o foco narrativo

Los últimos casos de funcionalización narrativa difieren de los anteriores en que no son los personajes los que cambian de lugar, sino que se trata de un cambio en la perspectiva del público, atraído de un lugar de la narración a otro:

(21) Nonbrados son los que irán en el algara e los que con mio Cid ficarán en la çaga (vv. 454-455).

Afevos los dozientos e tres en el algara, e sin dubda corren...;

fasta Alcalá llegó la seña de Minaya e desí arriba tórnanse con la ganancia, Fenares arriba e por Guadalfajara (vv. 476-479).

(22) Dozientos cavalleros mandó exir privado, que reciban a Minaya e a las dueñas fijasdalgo.

Él sedié en Valencia curiando e guardando, ca bien sabe que Álbar Fáñez trae todo recabdo. Afevos todos aquestos reciben a Minaya e a las dueñas e a las niñas e a las otras conpañas (vv. 15641569).

(23) Ya salieron al campo do eran los mojones. Todos tres son acordados los del Campeador que cada uno d'ellos bien fos ferir el so. Fevos de la otra part los ifantes de Carrión, muy bien aconpañados, ca muchos parientes son (vv. 35883592).

En (21), después de haber narrado lo que ocurre en la retaguardia (çaga), el narrador dirige la atención de su público a los eventos simultáneos relacionados con los hombres de la vanguardia (algara) (cf. Montaner 2011a, v. 476). Estos cambios de perspectiva corresponden a una composición y una técnica narrativas que se pueden asociar al concepto de entrelacement $t^{31}$. Como parte de esta técnica, la construcción $<(a) h e ́ \mathrm{SN}>$ se usa, por tanto, como fórmula que marca el cambio de foco narrativo y concierne, exclusivamente, a la perspectiva del público ${ }^{32}$.

${ }^{31}$ El concepto fue introducido por Lot (1918) en su estudio del Lancelot en prose.

32 Luongo (2018, p. 214) habla de un "demarcating verse". 
De modo parecido se funcionaliza la construcción en (22) y (23): En (22) marca un salto temporal desde la orden de recibir a Álvar Fáñez hasta la recepción de éste; en (23) dirige la atención dentro de la misma escena hacia los oponentes del Cid. Aquí llama la atención que el marcado del cambio de foco narrativo siempre va acompañado por estrategias mirativas, es decir, por el marcado de la relevancia -para el público $(c)$ - de lo destacado por $(a) h e^{33}$. En este sentido, sin duda -a diferencia de los casos discutidos anteriormente, donde parece más opcional $^{34}$-, no hay nada azaroso en que aquí la construcción deíctico-presentativa integre siempre el pronombre vos. Este dativo ético (cf. supra, n. 21) asume, si no en general por lo menos en este contexto, la función mirativa de marcar lo mostrado como relevante para el público. Los casos aquí descritos también presentan importantes diferencias sintácticas respecto de los anteriores: los SN introducidos no se refieren a entidades que irrumpen novedosamente en la escena, sino que aún están presentes en el espacio discursivo actual (aunque ya no inmediato) por haber sido mencionadas poco antes. Se trata, pues, de entornos de recuperación de tópico -a veces subrayado por la recuperación del evento entero, como en (22) con recibir-, una forma de cambio que reintroduce un referente o tópico ya presente en el espacio discursivo.

\section{Conclusiones y PERSPECTIVAS}

Nuestro análisis ha intentado mostrar que el estudio del funcionamiento discursivo de las construcciones encabezadas por (a)hé, y en particular de su uso narrativo, representa una empresa provechosa que merece más atención tanto desde un punto de vista lingüístico como filológico. Como hemos visto, las construcciones deíctico-presentativas, en cuanto potenciales expresiones mirativas, desempeñan no solamente funciones discursivas en el ámbito de la enunciación, como el dirigir de modo expresivo la atención del público dentro de una escena, sino también funciones macrotextuales cuando estructu-

33 Acerca del uso de expresiones mirativas para fines macrotextuales, como el de marcar el "main point of the story", cf. KöNIG 2013.

${ }^{34}$ Se integra asimismo en las ocurrencias (4) -aquí en discurso directo-, (8) y (16). 
ran la narración y marcan puntos clave del poema épico. Lo que aún queda por estudiar son los usos de esta construcción y de construcciones parecidas en otros textos y otras tradiciones discursivas medievales. Por un lado, muchas ocurrencias en el Cantar recuerdan usos y expresiones que de forma parecida se documentan en textos épicos y novelas caballerescas de otras literaturas románicas. Por otro, ya en la Biblia se encuentran estrategias narrativas semejantes, no solamente en las traducciones al castellano, sino también en las versiones hebrea, griega y latina. Aún no queda claro dónde tienen exactamente su origen estas funcionalizaciones de actos de mostración lingüísticos; si surgen, por primera vez, en la literatura antigua y bíblica para influenciarse mutuamente o si, tal vez, se trate de afinidades y estrategias narrativas universales.

\section{REFERENCIAS}

\section{Corpus}

Cantar de mio Cid. Ed., estudio y notas de Alberto Montaner, con un ensayo de Francisco Rico, Círculo de Lectores-Espasa Calpe, Barcelona-Madrid.

\section{Repertorios lexicográficos}

$D A A L=$ Federico Corriente 2008. Dictionary of Arabic and allied loanwords: Spanish, Portuguese, Catalan, Galician and Kindred dialects, Brill, LeidenBoston.

DCECH = Joan Coromines y José A. Pascual 1991-1997. Diccionario crítico etimológico castellano e hispánico, Gredos, Madrid, 6 ts.

$D E A$ = Manuel Seco, Olimpia Andrés y Gabino Ramos 1999. Diccionario del español actual, Aguilar, Madrid, 2 ts.

$D F D A=$ Federico Corriente, Christophe Pereira y Ángeles Vicente 2017. Dictionnaire du faisceau dialectal arabe andalou. Perspectives phraséologiques et étymologiques, De Gruyter, Berlin-Boston.

DiEz, FrIEDRICH 1887 [1853]. Etymologisches Wörterbuch der romanischen Sprachen, 5. Aufl., Marcus, Bonn.

$D L E=$ Real Academia Española 2014. Diccionario de la lengua española, $23^{\mathrm{a}}$ ed., Espasa, Madrid.

DUE = María Moliner 2007. Diccionario de uso del español, $3^{\text {a }}$ ed., Gredos, Madrid.

Menéndez Pidal, Ramón 1911. Cantar de mio Cid. Texto, gramática y vocabulario. Tercera parte: Vocabulario, Bailly-Baillière, Madrid. 
$O L D=$ P.G.W. Glare 2010. Oxford Latin Dictionary, Oxford University Press, Oxford.

REW = Wilhelm Meyer-Lübke 1911. Romanisches Etymologisches Wörterbuch , Winter, Heidelberg. [La $3^{\text {a }}$ ed. mencionada en el texto, publicada también por Winter, corresponde a 1936].

$T L L=$ Thesaurus linguae latinae . Editus auctoritate et consilio Academiarum quinque Germanicarum Berolinensis Gottingensis Lipsiensis Monacensis Vindobonensis (1900 ff.), Leipzig.

\section{Referencias bibliográficas}

Aikhenvald, Alexandra Y. 2012. "The essence of mirativity", Linguistic Typology, 16, pp. 435-485; doi: 10.1515/lity-2012-0017.

Aikhenvald, Alexandra Y. (ed.) 2018. The Oxford Handbook of evidentiality, Oxford University Press, Oxford.

Ascoli, Graziadio Isaia 1886-88. "Di un filone italico, diverso dal romano, che si avverta nel campo neolatino. Lettera a Napoleone Caix", Archivio Glottologico Italiano, 10, pp. 1-17.

Bello, ANDrés 1860 [1847]. Gramática de la lengua castellana, destinada al uso de los americanos, $5^{\mathrm{a}}$ ed., Imprenta y Librería del Mercurio de Santos Tornero, Valparaíso.

Bergen, Benjamin K. \& Madelaine C. Plauché 2005. "The convergent evolution of radial constructions. French and English deictics and existentials", Cognitive Linguistics, 16, pp. 1-42; doi: 0.1515/cogl.2005.16.1.1.

BüHler, Karl 1950. Teoría del lenguaje, Revista de Occidente, Madrid.

Chafe, Wallace 1994. Discourse, consciousness, and time. The flow and displacement of conscious experience in speaking and writing, University of Chicago Press, Chicago.

Company Company, Concepción (dir.) 2006. Sintaxis histórica de la lengua española. Primera parte: La frase verbal, Universidad Nacional Autónoma de México, México.

Corriente, Federico 2018. La investigación de los arabismos del castellano en registros normales, folklóricos y bajos. Discurso leído el día 20 de mayo de 2018 en su recepción pública, Real Academia Española, Madrid.

Corriente, Federico 2018a. "On the Arabic loanwords in the Poema de mio Cid", en A Companion to the "Poema de mio Cid". Coords. Irene Zaderenko \& Alberto Montaner, Brill, Leiden-Boston, pp. 169-180.

Corriente, Federico, Christophe Pereira et Ángeles Vicente (éds.) 2015. Aperçu grammatical du faisceau dialectal arabe andalou. Perspectives synchroniques, diachroniques et panchroniques, De Gruyter, Berlin-Boston.

Coseriu, Eugenio 1992. Competencia lingüistica. Elementos de la teoría del hablar, Gredos, Madrid.

Coseriu, Eugenio 1996. El sistema verbal románico. Comp. y red. Hansbert Bertsch. Trad. Carlos Opazo Velásquez, Siglo XXI, Madrid.

Croft, William 2001. Radical construction grammar: Syntactic theory in typological perspective, Oxford University Press, Oxford. 
Cruschina, Silvio 2019. "Focus fronting in Spanish: Mirative implicature and information structure", Probus, 31, pp. 119-146; doi: 10.1515/probus-2018-0008.

Curtius, Ernst Robert 1949. "Antike Rhetorik und Vergleichende Literaturwissenschaft”, Comparative Literature, 1, pp. 24-43; doi: $10.2307 / 1768458$.

De Benito Moreno, Carlota 2016. "La pronominalización en las construcciones existenciales con haber: ¿hay restricciones o no las hay?”, en En torno a "haber". Construcciones, usos y variación desde el latín hasta la actualidad. Coords. Carlota de Benito Moreno y Álvaro S. Octavio de Toledo y Huerta, Frankfurt/M., Peter Lang, pp. 209-237.

DeLancey, Scott 1997. "Mirativity: The grammatical marking of unexpected information”, Linguistic Typology, 1, pp. 33-52; doi: 10.1515/ lity.1997.1.1.33.

DeLancey, Sсотt 2001. "The mirative and evidentiality", Journal of Pragmatics, 33, pp. 369-382; doi: 10.1016/S0378-2166(01)80001-1.

DeLancey, Scott 2012. "Still mirative after all these years", Linguistic Typology, 16, pp. 529-564; doi: 10.1515/lity-2012-0020.

EnriQue-Arias, Andrés y Laura Camargo Fernández 2015. "Problemas en torno a la caracterización de un marcador del discurso en español medieval: el caso de $h e$ ", en Les marqueurs du discours dans les langues romanes: une approche contrastive. Coords. Margarita Borreguero Zuloaga et Sonia Gómez-Jordana Ferary, Lambert-Lucas, Limoges, pp. 323-331.

Ford, Jeremiah D.M. 1903. "Old Spanish etymologies. Old Spanish afe, fe, etc.”, Modern Philology, 1, pp. 49-55; doi: 10.1086/386579.

García-Miguel, José María 2006. "Los complementos locativos”, en Sintaxis histórica de la lengua española. Primera parte: La frase verbal. Dir. Concepción Company Company, Universidad Nacional Autónoma de México, México, pp. 1253-1336.

Goldberg, Adele E. 1995. Constructions: A construction grammar approach to argument structure, University of Chicago Press, Chicago.

Goldberg, Adele E. 2006. Constructions at work: The nature of generalization in language, Oxford University Press, Oxford.

Imbs, PAUl 1956. Les propositions temporelles en ancien français. La détermination du moment. Contribution à l'étude du temps grammatical français, Publications de la Faculté des Lettres de l'Université de Strasbourg, Strasbourg.

Karssenberg, Lena, Karen Lahousse et Stefania Marzo 2018. "Les clivées en voici/ voilà. Une analyse de corpus", Lingvisticae Investigationes, 41, pp. $129-151$.

KöNIG, CHRISTA 2013. "Source of information and unexpected information in !xun-evidential, mirative and counterexpectation markers", en Perception and cognition in language and culture. Coords. Anne Storch \& Alexandra Aikhenvald, Brill, Leiden, pp. 69-94.

LAKOFF, GEORGE 1987. Women, fire, and dangerous things. What categories reveal about the mind, University of Chicago Press, Chicago.

LAMBRECHT, KNUd 1994. Information structure and sentence form. Topic, focus and the mental representations of discourse referents, Cambridge University Press, Cambridge. 
LAmbrecht, Knud 2000. "Prédication seconde et structure informationnelle: la relative de perception comme construction présentative", Langue Française, 127, pp. 49-66; doi: 10.3406/lfr.2000.998.

Langacker, Ronald W. 1987. Foundations of cognitive grammar, Stanford University Press, Stanford.

LANGACKer, RONALD W. 2001. "Discourse in cognitive grammar", Cognitive Linguistics, 12, 2, pp. 143-188; doi: 10.1515/cogl.12.2.143.

LANGacker, Ronald W. 2008. Cognitive grammar. A basic introduction, Oxford University Press, Oxford.

LÉARD, JEAN-Marcel 1992. Les gallicismes. Étude syntaxique et sémantique, Duculot, Paris.

Lot, Ferdinand 1918. Étude sur le "Lancelot en prose", Champion, Paris.

Luongo, Salvatore 2018. "«Mio Cid Ruy Díaz odredes lo que dixo»: The voice of the narrator, the voice of the characters", en A Companion to the "Poema de mio Cid". Coords. I. Zaderenko \& A. Montaner, Brill, LeidenBoston, pp. 207-246.

Malkiel, Yakov 1982. "Between monogenesis and polygenesis", en Papers from the Third International Conference on Historical Linguistics, Hamburg, August 22-26, 1977. Coords. Peter J. Maher, Allan R. Bomhard \& E.F. Konrad Koerner, John Benjamins, Amsterdam, pp. 235-272.

Marnette, Sophie 1998. Narrateur et point de vue dans la littérature française médiévale. Une approche linguistique, Lang, Bern.

Marnette, Sophie 1999. "Narrateur et point de vue dans les croniques médiévales. Une approche linguistique", en The Medieval chronicle. Proceedings of the 1st International Conference on the Medieval Chronicle (Driebergen-Utrecht 13-16 July 1996). Coord. Erik Kooper, Rodopi, Amsterdam-Atlanta, pp. 174-190.

Meyer-LüBke, Wilhelm 1890-1902. Grammatik der romanischen Sprachen, Reisland, Leipzig, 4 ts.

Miller-Naudé, Cynthia L. \& Christo H. J. van der Merwe 2011. "ה הagֵ and mirativity", Biblical Hebrew Studies, 52, pp. 53-81.

Montaner, Alberto 2011. "El «Cantar de mio Cid»", en Cantar de mio Cid. Ed., estudio y notas de A. Montaner, con un ensayo de F. Rico, Círculo de Lectores-Espasa Calpe, Barcelona-Madrid, pp. 257-560.

Montaner, Alberto 2011a. "Notas", en Cantar de mio Cid. Ed., estudio y notas de A. Montaner, con un ensayo de F. Rico, Círculo de LectoresEspasa Calpe, Barcelona-Madrid.

$N G L E=$ Real Academia Española y Asociación de Academias de la Lengua Española 2009. Nueva gramática de la lengua española. Morfología y sintaxis, Espasa, Madrid, 2 ts.

Oppermann-Marsaux, Evelyne 2006. "Les origines du présentatif voici/ voilà et son évolution jusqu'à la fin du $\mathrm{xvi}^{\mathrm{e}}$ siècle”, Langue Française, 149 (Énonciation et pragmatique: approche diachronique), pp. 77-91; doi: 10.3917/lf.149.0077.

Oppermann-Marsaux, Evelyne 2007. "L'évolution du présentatif veez ci/ la en français mediéval ( $\mathrm{xI}^{\mathrm{e}}-\mathrm{XV}^{\mathrm{e}}$ siècles)", en Études sur le changement linguistique en français. Coords. Bernard Combette et Christiane MarchelloNizia, Presses Universitaires de Nancy, Nancy, pp. 235-245. 
Pietsch, Karl 1904. "The Spanish particle he”, Modern Philology, 2, pp. 197224; doi: 10.1086/386636.

Pietsch, Karl 1904a. "Spanish he (he aquî)", Modern Language Notes, 19, p. 62; doi: $10.2307 / 2917487$.

Poema de mio Cid 1929. $3^{\text {a }}$ ed. corr. Notas de Ramón Menéndez Pidal, Clásicos Castellanos, Madrid.

Pons Rodríguez, Lola 2014. “¿Hay la intuición? La historia de la lengua española y el efecto de definitud”, Rilce. Revista de Filología Hispánica, 30 , pp. 807-832.

Rico, Francisco 2011. "Un canto de frontera: «La gesta de Mio Cid el de Bivar»", en Cantar de mio Cid. Ed., estudio y notas de A. Montaner, con un ensayo de F. Rico, Círculo de Lectores-Espasa Calpe, Barcelona-Madrid, pp. 221-255.

RidRUejo, Emilio 2007. "Problemas metodológicos en pragmática histórica", en Actes du XXIVe Congres International de Linguistique et de Philologie Romanes. Coord. David Trotter, Niemeyer, Tübingen, t. 3, pp. 533-552.

Rodríguez Molina, Javier 2018. "A closer look at the Poema de mio Cid's language", en A Companion to the "Poema de mio Cid". Coords. I. Zaderenko \& A. Montaner, Brill, Leiden-Boston, pp. 137-168.

TACKe, Felix 2020. Aufmerksamkeitslenkung in den romanischen Sprachen. Historische Syntax und Pragmatik von Zeigeaktkonstruktionen, Philosophische Fakultät der Rheinischen Friedrich-Wilhelms-Universität Bonn, Bonn.

TACKe, Felix 2020a. "Notizen zu einer historisch-vergleichenden kognitiven Grammatik", en Fachbewusstsein der Romanistik. Romanistisches Kolloquium XXXII. Hrsg. Lidia Becker, Julia Kuhn, Christina Ossenkop, Anja Overbeck, Claudia Polzin-Haumann und Elton Prifti, Narr, Tübingen, pp. 73-102.

TACKE, Felix en prensa. "From he aqui to aquí está. A case of constructional substitution and syntactic regularization", en Constructions in Spanish. Coords. Inga Hennecke \& Evelyn Wiesinger, John Benjamins, Amsterdam-Philadelphia.

TACKe, Felix en prensa a. "Ampliando la perspectiva: acerca de la problemática categorización de (a)héy sus cognados románicos”, en Actas del XI Congreso Internacional de Historia de la Lengua Española (Lima, agosto 2018). Coords. Álvaro Ezcurra y Carlos Garatea Grau, Lang, Bern.

Tobler, Adolf 1899. "Relativsatz als prädikative Bestimmung", en Vermischte Beiträge zur Französischen Grammatik III, Hirzel, Leipzig, pp. 63-67.

Tomasello, Michael 2008. Origins of human communication, MIT Press, Cambridge, MA.

Viejo SÁnchez, María Luisa 2017. "Usos y valores de ahê", en La fraseología a través de la historia de la lengua española y su historiografía. Coords. María Echenique Elizondo y María José Martínez Alcalde, Tirant Humanidades, Valencia, pp. 155-172.

Wehr, Barbara 1984. Diskurs-Strategien im Romanischen. Ein Beitrag zur romanischen Syntax, Narr, Tübingen.

Zaderenko, Irene \& Alberto Montaner 2018. "Introduction", en A Companion to the "Poema de mio Cid". Coords. I. Zaderenko \& A. Montaner, Brill, Leiden-Boston, pp. 1-40. 
Zafiu, Rodica 2015. "Presentative markers in Old Romanian: Divergent changes in the syntactic and pragmatic uses of adică and iată", en Diachronic variation in Romanian. Coords. Gabriela Pană Dindelegan, Rodica Zafiu, Adina Dragomirescu, Irina Nicula \& Alexandru Nicolae, Cambridge Scholars Publishing, Newcastle upon Tyne, pp. 425-453. 